\title{
Solid Pseudopapillary Neoplasm of Pancreas In A35 Year Old Lady
}

\author{
Imdad S ${ }^{1}$, Saha PK ${ }^{2}$, Rahman MM³ ${\text { Hoque } \text { MM}^{4} \text {, Saha KP }}^{5}$, Ahmed FU ${ }^{6}$, Aziz NMSB ${ }^{7}$
}

Conflict of Interest: None

Received: 10 January 2017

Accepted: 20 May 2017

www.banglajol.info/index.php/JSSMC

Key Words:

Solid pseudopapillary neoplasm of pancreas, Chronic pancreatitis,

pancreatic pseudocyst.

\begin{abstract}
:
Solid pseudopapillary neoplasm of pancreas (SPN) is a rare entity; therefore proper diagnosis, evaluation and formulation of treatment protocols is difficult. The commonest presenting symptom is abdominal pain. This article presents a case of solid pseudopapillary neoplasm of pancreas in a 35 years old lady. A high index of clinical suspicion is necessary to suspect and diagnose SPN. This diagnosis should be borne in mind when young female patients present with a pancreatic mass.
\end{abstract}

[J Shaheed Suhrawardy Med Coll 2017; 9(1): 31-34] DOI: http://dx.doi.org/10.3329/jssmc.v9i1.37257

\section{Introduction:}

Solid pseudopapillary neoplasm of pancreas (SPN) is a low grade malignancy composed of poorly cohesive monomorphic epithelial cells forming solid and pseudopapillary structures (WHO). It derives from centroacinar cells Not truly papillary or truly cystic. Also called SPT, papillary and solid epithelial neoplasm, papillary cystic neoplasm, Gruber-Frantz tumor. It comprises 1-2\% of non-endocrine pancreatic neoplasm. Mean age 30-35 years, $90 \%$ women, not associated with any clinical syndrome most of the time. ${ }^{1,2,3}$

\section{Case Report :}

Mrs. Minara Begum, 35 years, from Laxipur was admitted in Shaheed Suhrawardy Medical College Hospital with complaints of recurrent left upper abdominal pain for 2 years which was dull aching, moderate in intensity, sometimes radiate to back with no aggravating factors but relieved by taking medication (usually oral) and not associated with vomiting. Each episode of pain usually persist for 7 to 10 days and recur with an irregular interval. A gradually increasing, painful lump was noticed in left upper abdomen for last 2 months. She had anorexia, fullness after meal, fatty food intolerance, losing almost $4 \mathrm{~kg}$ weight

1. Dr. Sadia Imdad, Junior Consultant, Department of Surgery, ShSMCH

2. Prof. Pankaj Kumar Saha, Professor n Head, Department of Surgery, ShSMCH

3. Prof. Md. Mustafizur Rahman, Professor, Department of Surgery, ShSMCH

4. Dr. Md. Mozammal Hoque, Associate Professor, Department of Surgery, ShSMCH

5. Dr. Krishna Pada Saha, Junior Consultant, Department of Surgery, ShSMCH

6. Dr. Farhad Uddin Ahmed, Junior Consultant, Department of Surgery, ShSMCH

7. Dr. Nur Mohammod Sayed Bin Aziz, Junior Consultant, Department of Surgery, ShSMCH

Correspondence to: Dr. Sadia Imdad, Junior Consultant, Department of Surgery, ShSMCH within last two months. There was no history of jaundice, haemoptysis, chest pain, haematemesis, melaena, haematuria, bone pain, evening rise of temperature or contact with TB patient. Her bowel- bladder habit was normal. On physical examination she was ill looking with below average body built, severely malnourished, moderately anaemic, non icteric, all of her vital parameters were within normal limits. There was a mildly tender lump in left hypochondriac and partly in left lumber region measuring about $10 \times 8 \mathrm{~cm}$ in diameter, globular shape, smooth surface, ill defined margin, firm in consistency, free from anterior abdominal wall, moves side to side but restricted above downward and also not moves with respiration, less prominent in knee- elbow position with no rise of local temperature. There was no organomegaly. All other systemic examination revealed no abnormalities.

\section{Table-I}

Biochemical Parameters

Test

Result

Complete Blood Count

Hemoglobin

$8.4 \mathrm{gm} / \mathrm{dl}$

ESR::

$32 \mathrm{~mm} / 1 \mathrm{st}$ hour

Total count of WBC

6300/cum

Differential counts :

$\begin{array}{lc}\text { Neutrophil } & 58 \% \\ \text { Lymphocyte: } & 36 \% \\ \text { Monocyte } & 02 \%, \\ \text { Eosinophil:. } & 04 \% \\ \text { se: } & 97 \mathrm{U} / \mathrm{L} \\ 9 \text { - } & 5.50 \mathrm{U} / \mathrm{ml}\end{array}$


USG revealed a well-defined rounded complex mass having solid and cystic component with internal septation and fatty component present within it, measuring about $11 \times 9.4 \mathrm{~cm}$ extending from left hypochondriac to left lumber region. CT scan report showed an oval mixed density lesion predominantly cystic having internal calcification measuring about $11.01 \times 11.5 \mathrm{~cm}$ in left hypochondriac \& lumber region posterior to the stomach, anterior to left kidney compressing the kidney posteriorly, displacing the stomach upwards. The mass could not be separated from the tail of the pancreas and after I/V contrast no abnormal enhancement is noted. USG guided FNAC shows few round cells and inflammatory cells in a background of RBCs but no malignant cell.

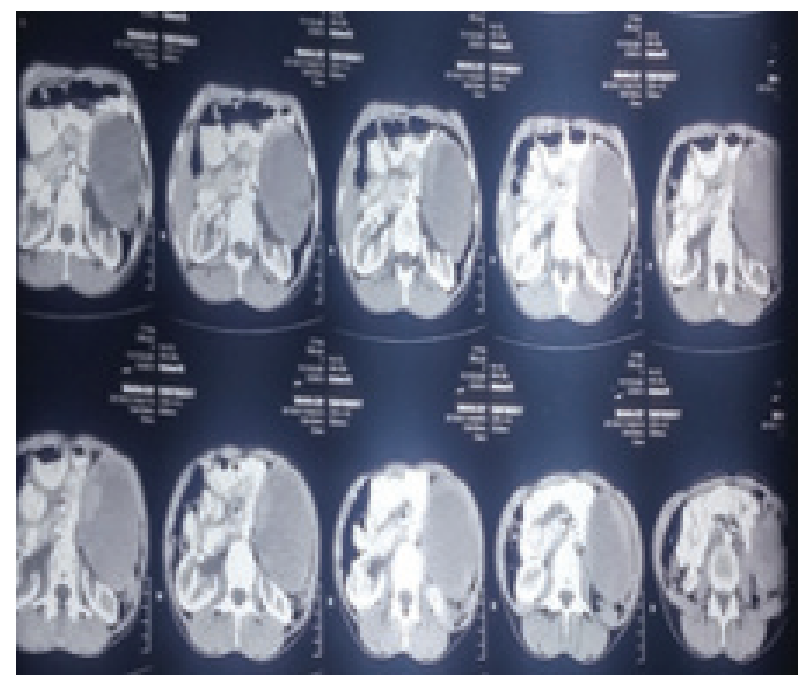

Fig.-1: CT Scan of Abdomen Axial View

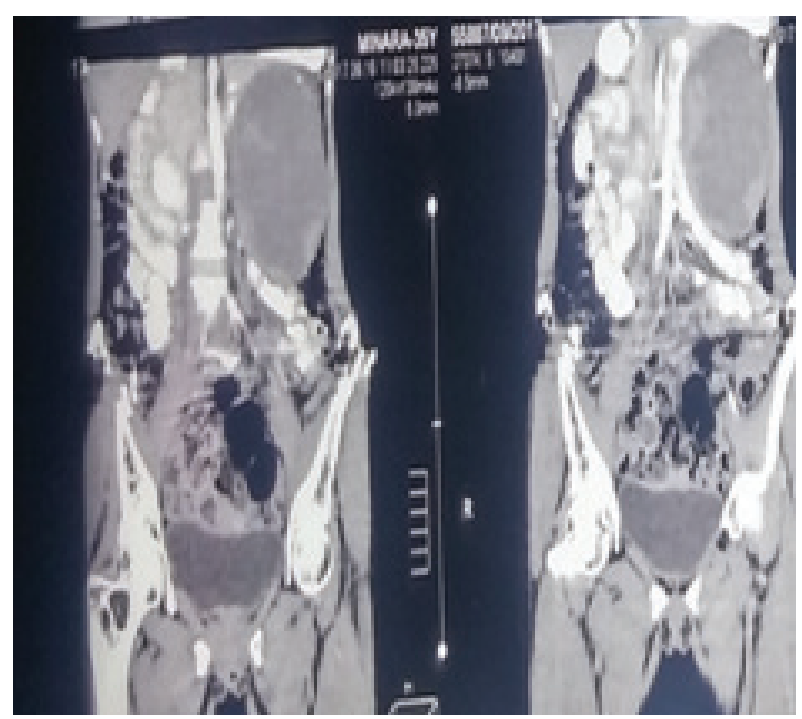

Fig.-2: CT scan of Abdomen Coronal View
After proper counselling and preparation laparotomy was done with a view that it is a pancreatic pseudocyst. Peroperative findings was a retroperitoneal mass on left hypochondriac and partly left lumber region with well defined margin and adherent to surrounding structures. There was no lesion in the liver and peritoneal cavity was free from any seedling. The mass was separated from surrounding structures including hilum of the spleen and found arising from tail of pancreas. Lump was adherent to few engorged segmental splenic vessels which were separated later, one was ligated. Lump was removed with part of pancreatic tail without disturbing the duct. Pancreatic tail was sutured by prolene. Proper hemostasis was maintained. Abdomen was closed in layers after keeping 2 drains, 1 in left subhepatic and another in pelvis.

Resected specimen was sent for histopathology. Sections reveal a solid pseudopapillarytumour of pancreas. It is made of uniform polygonal cells arranged around small thin walled blood vessels. Focal hemorrhage, hyalinized areas and a thin fibrous capsule are seen. No malignancy is seen. Post-operative period was uneventful. Oncological consultation was sought and patient was discharged with a proper follow up schedule.

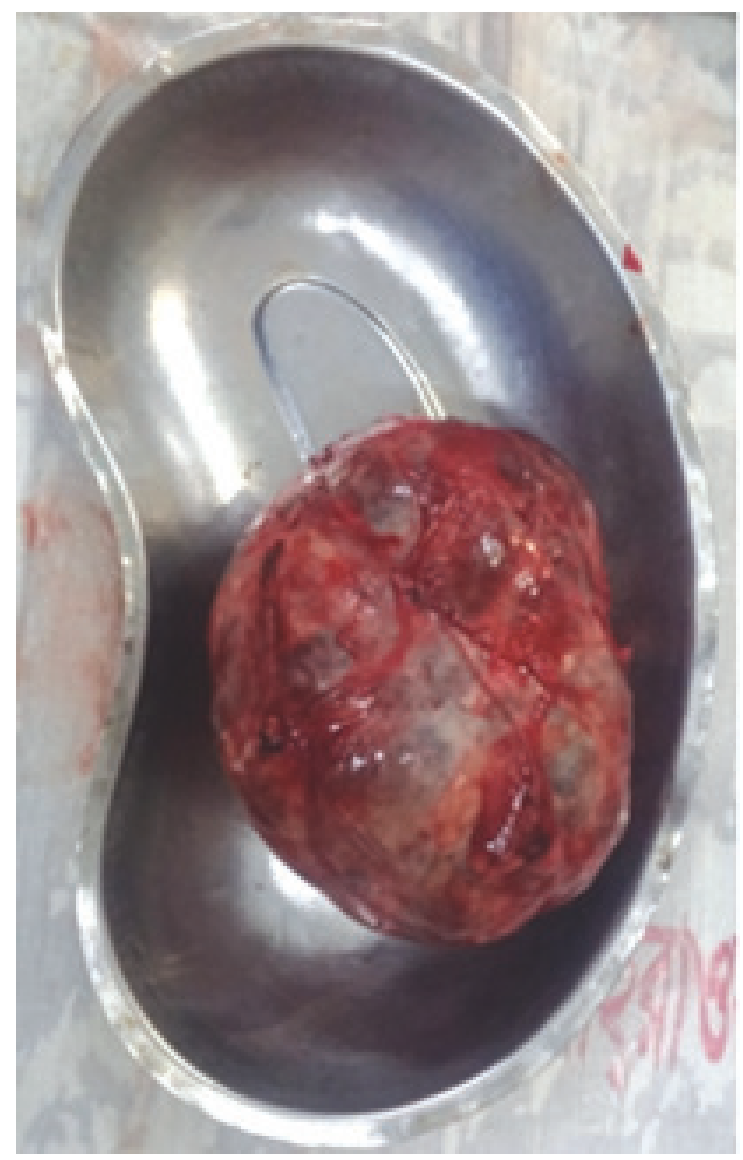

Fig.-3: Operative Specimen 


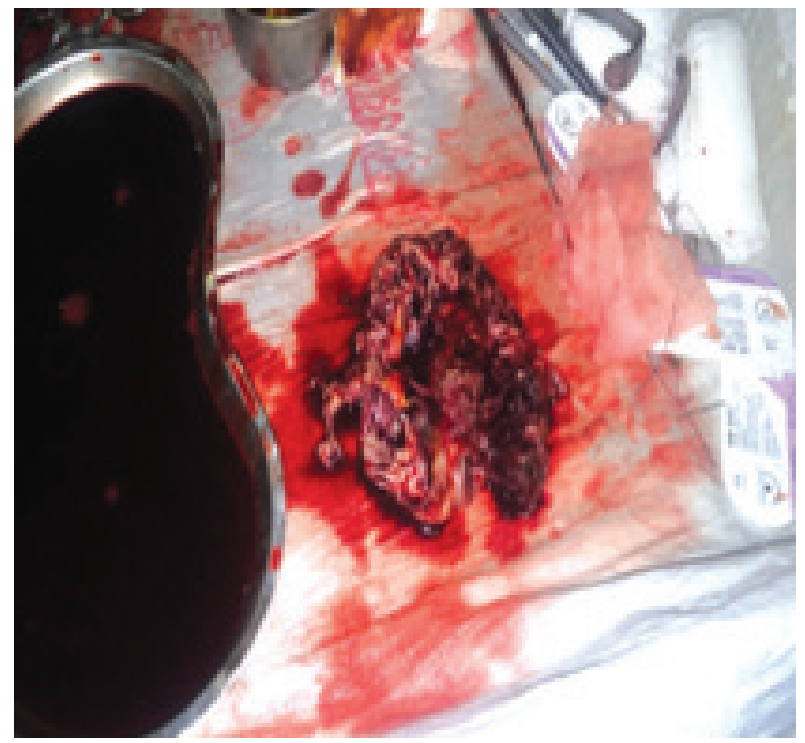

Fig.-4: Operative Specimen(Transected)

\section{Discussion :}

SPN is very rare; in fact, they only constitute about $5 \%$ of cystic pancreatic tumors and about 1 to $2 \%$ of exocrine pancreatic neoplasms. They present mainly in the second and third decades of life. The origin of solid pseudopapillary tumors still remains unclear. These neoplasms have been suggested to have a ductal epithelial, neuroendocrine, multipotent primordial cell, or even an extra-pancreatic genital ridge angle-related cell origin. The clinical presentation of the tumor is usually nonspecific. Abdominal discomfort or vague pain is the most common symptom, followed by a gradually enlarging mass and compression signs induced by the tumor. Some patients are completely asymptomatic, with the tumor detected incidentally by imaging studies or routine physical examination. Usually there is no evidence of pancreatic insufficiency, abnormal liver function tests, cholestasis, elevated pancreatic enzymes or an endocrine syndrome. Tumor markers are also generally unremarkable ${ }^{4,5}$ although some showraised level of CA-19-9.

SPN can occur in every part of the pancreas but they are slightly more common in the tail ${ }^{6}$. Grossly, it appears as a large and encapsulated mass, generally well-demarcated from the remaining pancreas. In fact, invasion of the adjacent organs, such as the spleen or the duodenal wall, is rare. Depending on the tumor position (head, body or tail of the pancreas), the differential diagnosis includes adrenal mass, pancreatic endocrine tumor, liver cyst or tumor, or a pseudocyst ${ }^{7}$.

Abdominal ultrasound and CT show a well encapsulated, complex mass with both solid and cystic components and displacement of nearby structures. There may be calcifications at the periphery of the mass and intravenous contrast enhancement inside the mass suggesting hemorrhagic necrosis ${ }^{8}$ However, when compared with MR imaging, CT has inherent limitations in showing certain tissue characteristics, such as hemorrhage, cystic degeneration, or the presence of a capsule. These features may be suggestive of specific lesions such as SPN of the pancreas. Therefore, MR imaging may further aid in showing these characteristics and in the differential diagnosis of complex cystic masses within the pancreas ${ }^{9} \cdot$ Despite the technological improvements, preoperative diagnosis is difficult because of the similarity of findings among cystic lesions. Some studies advocate preoperative endosonography guided fine-needle aspiration biopsy for preoperative detection of the tumor, but this may not be accepted by others because of the uncertainty in diagnosis and the possible tumor spread 10,11

In approximately $85 \%$ of the patients, SPN is limited to the pancreas, while about $10 \%$ to $15 \%$ of tumors have already metastasized at the time of presentation ${ }^{12}$. The most common sites for metastasis are the liver, regional lymph nodes, mesentery, omentum and peritoneum.

Once the diagnosis of SPN is made, surgery is the first choice of treatment. SPN is usually surrounded by a pseudocapsule and exhibits benign or low-grade malignancy. Conservative resection with preservation of as much pancreatic tissue as possible is the treatment of choice. According to the location of the tumor, distal pancreatectomy with or without splenectomy, pylorous preserving pancreatoduodenectomy, Whipple operation or enucleation can be performed. Many studies have demonstrated that less aggressive surgical procedures could be preferred for the treatment of SPN ${ }^{13}$. Extensive lymphatic dissection or more radical approaches are not indicated when the disease is localized. Local invasion and metastases are not contraindications for resection. Portal vein resection is advocated when there is evidence of tumor invasion. For the metastases, surgical debulking should be performed, in contrast to other pancreatic malignancies. Metastases can be removed with enucleations or hepatic lobectomies and some patients with unresectable SPN may also have a long term survival ${ }^{14}$ The overall five-year survival rate of patients with SPN is about $95 \%$

Malignant SPN, designated as a solid-pseudopapillary carcinoma, occurs in $15 \%$ of adult patients. According to the WHO classification system, these are: 1) solidpseudopapillary neoplasms with borderline malignancy potential; and 2) solid-pseudopapillary carcinomas. Criteria 
which distinguish potentially malignant tumors and which are classified as 'SP carcinoma' are: 1) angioinvasion; 2) perineural invasion; and 3) deep invasion of the surrounding pancreatic parenchyma. A recent study showed that some histological features, such as extensive necrosis, nuclear atypia, high mitotic rate, immunohistochemistry findings of expression of Ki-67 and sarcomatoid areas may be associated with aggressive behavior ${ }^{15}$

Adjuvant therapy is used only in a small number of patients because of the high resectability of SPN. The role of chemotherapy or chemoradiotherapy in the treatment of SPN is also unclear. In some studies, adjuvant chemotherapy and radiotherapy are reported in some unresectable cases with good results ${ }^{16}$.Neoadjuvant chemotherapy or chemoradiotherapy is also reported to have been successful in a few cases $17,18,19,20$

\section{Conclusions}

SPN is a rare neoplasm that primarily affects young women. The prognosis is favorable even in the presence of distant metastasis. Although surgical resection is generally curative, a close follow-up is advised in order to diagnose a local recurrence or distant metastasis and choose the proper therapeutic option for the patient.

\section{References}

1. Compagno J, Oertel JE, Kemzar M. Solid and papillary epithelial neoplasm of the pancreas, probably of small-duct origin: a clinico-pathological study of 52 cases (Abstract) Lab Invest. 1979;40:248-9.

2. Jagannath P, Bhansali MS, Murthy SK, Mohandas KM, Swaroop VS, DeSouza LJ. Solid and cystic papillary neoplasm of pancreas-a report of seven cases. Indian J Gastroenterol. 1994;13:112-14. [PubMed]

3. Mao C, Guvendi M, Domenico DR, Kim K, Thomford NR, Howard JM. Papillary cystic and solid tumors of the pancreas: a pancreatic embryonic tumor? Studies of three cases and cumulative review of the world's literature. Surgery. 1995;118:821-8. [PubMed]

4. Yu PF, Hu ZH, Wang XB, Guo JM, Cheng XD, Zhang YL, Xu Q: Solid pseudopapillary tumor of the pancreas: a review of 553 cases in Chinese literature. World J Gastroenterol. 2010, 16: 1209-1214. 10.3748/wjg.v16.i10.1209.

5. Papavramidis T, Papavramidis S: Solid pseudopapillary tumors of the pancreas: review of 718 patients reported in English literature. J Am Coll Surg. 2005, 200: 965-972. 10.1016/j.jamcollsurg.2005.02.011.

6. Klimstra DS, Wenig BM, Heffess CS: Solid pseudopapillary tumor of the pancreas: a typically cystic carcinoma of low malignant potential. Semin Diagn Pathol. 2000, 17: 66-80.

7. Canzonieri V, Berretta M, Buonadonna A, Libra M, Vasquez E, Barbagallo E, Bearz A, Berretta S: Solid pseudopapillary tumour of the pancreas. Lancet Oncol. 2003, 4: 255-256. 10.1016/S1470-2045(03)01038-6.
8. .Dong PR, Lu DS, Degregario F, Fell SC, Au A, Kadell BM: Solid and papillary neoplasm of the pancreas: Radiologicalpathological study of five cases and review of the literature. Clin Radiol. 1996, 51: 702-705. 10.1016/S00099260(96)80242-X.

9. Cantisani V, Mortele KJ, Levy A, Glickman JN, Ricci P, Passariello R, Ros PR, Silverman SG: MR imaging features of solid pseudopapillary tumor of the pancreas in adult and pediatric patients. Am J Roentgenol. 2003, 181: 395-401. 10.2214/ajr.181.2.1810395.

10. Bardales RH, Centeno B, Mallery JS, Lai R, Pochapin M, Guiter G, Stanley MW: Endoscopic ultrasound-guided fineneedle aspiration cytology diagnosis of solid-pseudopapillary tumor of the pancreas: a rare neoplasm of elusive origin but characteristic cytomorphologic features. Am J Clin Pathol. 2004, 121: 654-662. 10.1309/DKK2B9V4N0W26A8Q.

11. Raffel A, Cupisti K, Krausch M, Braunstein S, Trobs B, Goretzki PE, Willnow U: Therapeutic strategy of papillary cystic and solid neoplasm (PCSN): a rare non-endocrine tumor of pancreas in children. Surg Oncol. 2004, 13: 1-6. 10.1016/ j.suronc.2003.09.003.

12. Mao C, Guvendi M, Domenico DR, Kim K, Thomford NR, Howard JM: Papillary cystic and solid tumors of the pancreas: A pancreatic embryonic tumor? Studies of three cases and cumulative review of the world's literature. Surgery. 1995, 118: 821-828. 10.1016/S0039-6060(05)80271-5.

13. Zhang H, Liang TB, Wang WL, Shen Y, Ren GP, Zheng SS: Diagnosis and treatment of solid-pseudopapillary tumor of the pancreas. Hepatobiliary Pancreat Dis Int. 2006, 5: 454458 .

14. Tang LH, Aydin H, Brennan MF, Klimstra DS: Clinically aggressive solid pseudopapillary tumor of the pancreas. A report of two cases with components of undifferentiated carcinoma and a comparative clinicopathologic analysis of 34 conventional cases. Am J Surg Pathol. 2005, 29: 512519. 10.1097/01.pas.0000155159.28530.88.

15. Fried P, Cooper J, Balthazar E, Fazzini E, Newall J: A role for radiotherapy in the treatment of solid and papillary neoplasms of the pancreas. Cancer. 1985, 56: 2783-2785. 10.1002/ 1097-0142(19851215)56:12<2783

16. Matsuda Y, Imai Y, Kawata S, Nishikawa M, Miyoshi S, Saito R, Minami Y, Tarui S: Papillary cystic neoplasm of the pancreas with multiple hepatic metastases: a case report. Gastroenterology Jpn. 1987, 22: 379-384.

17. Strauss JF, Hirsch VJ, Rubey CN, Pollock M: Resection of a solid and papillary epithelial neoplasm of the pancreas following treatment with cisplatinum and 5-fluorouracil: a case report. Med Pediatr Oncol. 1993, 21: 365-367. 10.1002/ mpo.2950210511.

18. Das G, Bhuyan C, Das BK, Sharma JD, Saikia BJ, Purkystha $\mathrm{J}$ : Spleen-preserving distal pancreatectomy following neoadjuvant chemotheraphy for papillary solid and cystic neoplasm of pancreas. Indian J Gastroenterol. 2004, 23: 188189

19. Maffuz A, Bustamante FT, Silva JA, Torres-Vargas S: Preoperative gemcitabine for unresectable, solid pseudopapillary tumour of the pancreas. Lancet Oncol. 2005, 6: 185-186. 10.1016/S1470-2045(05)01770-5.

20. Zauls JA, Dragun AE, Sharma AK: Intensity-modulated radiation therapy for unresectable solid pseudopapillary tumor of the pancreas. Am J Clin Oncol. 2006, 29: 639-640. 10.1097/01.coc.0000190457.43060.fd. 